\title{
Optimized expression of Hfa protein increases Escherichia coli growth by enhancing acid resistance
}

\author{
Phuong $\mathrm{Vo}^{1}$ and Dokyun $\mathrm{Na}^{1}$ \\ ${ }^{1}$ Chung-Ang University
}

July 2, 2020

\begin{abstract}
Escherichia coli is a widely used platform for metabolic engineering, for fast growth and well-established engineering techniques. However, there has been a demand for faster growing E. coli for higher production of desired substances. Here, we optimized Hfq protein expression, which plays an essential role in stress response, to increase stress tolerance by designing the ribosome binding site of the hfq gene thereby increasing cell growth. As a result, Hfq expression correlated with growth rate, and its optimal expression increased the maximal optical density in the stationary phase by $30.9 \%$ relative to that in the wild-type E. coli. RNA-seq and network analyses revealed the upregulation of stress response genes specifically that of the gadE gene, a transcription factor involved in acid resistance. The optimized gadE expression also increased the optical density of E. coli by $22.8 \%$, while co-expression of hfq and gadE genes increased growth by up to $29.7 \%$. In conclusion, our optimized Hfq increased E. coli optical density by improving cellular stress response, specifically acid tolerance. The fast-growing E. coli constructed in this study would be a useful metabolic engineering platform for the production of proteins and other desired substances.
\end{abstract}

\section{Introduction}

The production of chemical substances and proteins from genetically engineered bacteria has been studied for decades for practical use (Schein, 1989), and metabolic engineering has proven the essential role of bacteria engineering and its practical usefulness in the industry (Jozala et al., 2016; Quianzon \& Cheikh, 2012; Sanchez-Garcia et al., 2016). For instance, recent advances in metabolic engineering make it possible to engineer bacteria or yeast cells for high and cost-effective production of recombinant therapeutic proteins such as insulin and growth hormones (Baeshen et al., 2014; Ferrer-Miralles et al., 2009; Rezaei \& ZarkeshEsfahani, 2012) and biofuels such as alcohols and fatty acid methyl and ethyl esters (Kalscheuer et al., 2006; S. K. Lee et al., 2008; Yoshimoto et al., 2002). Regarding recombinant protein production, there have been several strategies to increase protein titers. High copy-number plasmids have been used to produce larger amounts of desired proteins (Ramos et al., 2004; Son et al., 2016), but high copy-number plasmids often place a metabolic burden on host cells, which eventually decreases cell growth, reduces plasmid stability (Glick, 1995), and consequently decreases protein productivity (Bentley et al., 1990; Birnbaum \& Bailey, 1991). Optimization of promoter strength has been also used to obtain a high protein titer. Depending on the properties or activities of desired proteins, $e . g$. ., toxicity, transcriptional optimization often increases overall protein titers (Briand et al., 2016; Studier \& Moffatt, 1986; Tegel et al., 2011; Tolentino et al., 1992). Recently, the increase in bacterial growth rate or cell density has gained great interest to achieve higher production of proteins (Shiloach \& Fass, 2005). Several strategies for improving cell density of Escherichia coli are summarized in Table 1.

In this study, we developed an $E$. coli strain that had a higher growth rate by optimizing the expression level of Hfq protein. Hfq protein was originally discovered as a host factor for phage $\mathrm{Q}_{\beta}$ replication in $E$. coli (Kajitani \& Ishihama, 1991). The chaperone Hfq is an abundant $11 \mathrm{kDa}$ protein that forms hexametric rings and presents in several but not all bacteria (Dambach et al., 2013; Sittka et al., 2007). There have 
been several studies indicating that Hfq promotes the ability of host cells to resist stresses such as oxidative stress and low pH (Chao \& Vogel, 2010). In addition, studies have described the role of Hfq in the control of growth-related genes (Ali Azam et al., 1999; Kajitani et al., 1994). Therefore, we hypothesized that the optimization of Hfq expression could increase bacterial growth rate.

We designed the ribosome-binding site (RBS) of the $h f q$ gene to change its expression level by using RBSDesigner (Na \& Lee, 2010). Its native promoter remained intact so that its regulation was not disrupted, as the Hfq promoter is regulated in response to several diverse cellular circumstances, thus, replacement of the Hfq promoter may result in disruption of cellular systems and unexpected outcomes. Therefore, we designed various RBS sequences to control the level of Hfq protein expression without modifying its promoter. Thereafter, we investigated whether Hfq expression levels affect the growth rate of $E$. coli by cell growth rate measurement and RNA-seq data analysis.

\section{Material and Methods}

Bacterial strains, plasmids, and antibiotics

Bacterial strains and plasmids used in this study are listed in Table S1. The media used for $E$. coli cultures were Luria-Bertani broth (10 g Bacto Tryptone, 5 g yeast extract, and $10 \mathrm{~g} \mathrm{NaCl} / \mathrm{L}$ ) (Sezonov et al., 2007) and cells were cultured in 50-mL Erlenmeyer flasks at $37^{\circ} \mathrm{C}$ shaking incubator. Antibiotics were added at the following concentrations: chloramphenicol, $25 \mathrm{mg} / \mathrm{mL}$; and ampicillin, $100 \mathrm{mg} / \mathrm{mL}$.

Various hfq and gadE RBS sequences and plasmid construction

Different $E$. coli $h f q$ variants with a variety of translation efficiencies were designed by RBSDesigner. All constructed sequences of $h f q$ variants are described in Table S3. The gadE variants were constructed by the same process as $h f q$ variants. Three different $g a d E$ variants were designed by RBSDesigner (Table S3). Details of plasmids constructed are described in the Supporting Information. Sequences of primers and genes are shown in Table S2.

\section{E. coli growth measurement}

The growth of $E$. coli was determined by measuring the $\mathrm{OD}$ at $600 \mathrm{~nm}\left(\mathrm{OD}_{600}\right)$ with a spectrophotometer every $2 \mathrm{~h}$ for 14 or $16 \mathrm{~h}$ on the U-5100 UV-Visible spectrophotometer (Hitachi, Japan). All experiments were performed in triplicate. The [?]hfq $E$.coli DH5 $\alpha$ with a $h f q$ variant was compared with $E$.coli DH5 $\alpha$ and [?] hfq $E$. coli DH5 $\alpha$. in which an empty vector was introduced. $E$. coli DH5 $\alpha$ with gadEvariants was compared with E. coli DH5a.

Fluorimetry

To confirm expression levels of $h f q$ variants, the egfpgene was cloned downstream of the $h f q$ coding sequence. To increase the flexibility between Hfq and green fluorescent protein (GFP), a stretch of Gly and Ser residues ("GS" linker) was used to connect $h f q$ and egfp. Thereafter, the fluorescence intensity (Guava Easycyte HT BG Flow Cytometer, EMD Millipore, Billerica, MA, USA) of GFP was measured to determine the expression level of Hfq variants.

mRNA-seq analysis

To investigate the effect of $h f q$ variants on cellular gene expressions of $E$. coli, RNA-seq analysis was conducted. The $h f q$ variant 4 , which showed the highest growth rate was compared with [?]hfq E . coli DH5 $\alpha$ harboring an empty vector.

The number of reads for each gene was determined using HTSeq (Anders et al., 2015). To reduce gene length bias, Reads Per Kilobase Million (RPKM) of each gene were calculated by dividing the total number of read count aligned to a gene by 1,000,000 and by the length of the gene in kilobase (Mortazavi et al., 2008).

To identify differentially expressed genes (DEGs), genes were filtered as the following criteria: $\mid($ fold change $) \mid>2 ; p$-value $<0.05 ;$ and normalized read count $\geq 10$. Gene Ontology (GO) 
and Kyoto Encyclopedia of Genes and Genomes (KEGG) enrichments of DEGs were analyzed by the Database for Annotation, Visualization and Integrated Discovery (DAVID) (Huang da et al., 2009). Enriched GO terms and KEGG pathways were selected by a p-value $<0.05$.

The protein-protein interaction (PPI) network of DEGs was constructed using the STRING database (Szklarczyk et al., 2017) and Cytoscape (Shannon et al., 2003). Highly interconnected clusters were identified using Molecular Complex Detection (MCODE) (Bader \& Hogue, 2003).

\section{Results and Discussion}

Role of Hfq protein in cell growth

The host factor for phage $\mathrm{Q}_{\beta}$ replication is known as a global regulator. Hfa has been shown to be involved in the stability of several RNAs (Caron et al., 2010; Hernandez-Arranz et al., 2016), the activity of some proteins involved in mRNA turnover such as RNase E (Vytvytska et al., 1998), polynucleotide phosphorylase, and poly(A) polymerase (Folichon et al., 2003). RNase E has been shown to play an important role in $E$ . coli cell growth (Li \& Deutscher, 2002; Ow \& Kushner, 2002). Some other studies have shown that Hfq protein is closely related with cell growth (Ali Azam et al., 1999; Jain et al., 2002) and is also associated with stress resistance in E .coli (Chao \& Vogel, 2010). Moreover, Hfq has been shown to be crucial for cell survival under nutrient limitation (Gottesman et al., 2006).

Therefore, we hypothesized that increased Hfq protein expression may promote cell growth by enhancing resistance to environmental stresses such as $\mathrm{pH}$. However, as the over-expression of Hfq protein may disrupt cellular physiology by extensive protein expression alteration, which may retard cell growth, we also hypothesized that the expression of Hfq protein must be exceptionally optimized.

Design of various RBS sequences to diversify the expression level of Hfq protein in E. coli

We designed five RBS variants of the $h f q$ gene to achieve the desired expression levels to modify Hfq protein production (Fig. 1A) and thereby increase cell growth. To avoid disrupting the inherent regulation of $h f q$ transcription, its native promoter was used without modification. Hence, five different $h f q$ RBS variants with different translational efficiencies were constructed using RBSDesigner (Table S3) (Na \& Lee, 2010). To maintain a low copy number of the $h f$ gene, the constructed genes were introduced into the pSC101 plasmid with only 1-2 copies in $E$. coli .

To confirm the expression levels of designed RBS variants, theegfp gene was fused at the C-terminal of the $h f q$ gene with a Gly-Ala linker. As $E$. coli already has one copy of thehfq gene in its genome, the genomic $h f q$ gene was knocked out (Table S1).

As shown in Figure 1B, the $h f q$ RBS variants predicted to have a higher translation efficiency demonstrated higher expression levels with the exception of variant 5 . The cells harboring $h f q$ variant 4 displayed the highest GFP signal. Expression level of $h f q$ variant 4 was approximately 6 -fold higher than that of the wild-type $h f q$ RBS in the exponential phase, whereas $h f q$ variant 1 demonstrated the lowest GFP intensity as expected, which was 135 -fold lower than that of $h f q$ variant 4 . This indicates that our variants successfully expressed Hfq proteins with the desired expression levels. However, variant 5, which was designed to have the highest expression level demonstrated a relatively low expression. As Hfq protein is a global regulator, over-expression may disrupt the physiological homeostasis and therefore retard cell growth. However, this is yet to be elucidated.

Fine optimization of Hfq expression increased E. coli growth

Variant 4 recorded the highest $\mathrm{OD}_{600}(4.59 \pm 0.13)$ in the stationary phase, which was $30.9 \%$ higher than that of wild-type $E$. coli $\mathrm{DH} 5 \alpha\left(\mathrm{OD}_{600}=3.51 \pm 0.095\right)$ (Fig. 1C). This indicates that variant 4 had improved cell growth and density. The $h f q$ variant 1 , which was designed to express the Hfq protein at the lowest level (Table S3), demonstrated the maximum $\mathrm{OD}_{600}$ of $3.23 \pm 0.19$. Other variants (hfqvariants 2, 3, and 5) demonstrated lower expression levels than variant 4 , and consequently, a lower maximum $\mathrm{OD}_{600}(3.80 \pm 0.16$, $3.70 \pm 0.10$, and $3.87 \pm 0.20$, respectively) than variant 4 . However, the $\mathrm{OD}_{600}$ values of variants 2,3 , and 
5 were still higher than that of wild-type cells. Consequently, the results signify that the optimal expression of Hfq protein resulted in increasing cell growth and achieving the highest cell density.

Differentially expressed genes and enrichment analyses

To determine the biological effect of Hfq expression levels on cellular physiology leading to an increase in bacterial growth, we performed RNA-seq analysis to discover up- and down-regulated genes of the two strains ( $h f q$ variant 4 and [?]hfq $E$. coli ) in the stationary phase. We found 446 DEGs with a $\mid \log _{2}$ (fold-change) $>2$ and $p$-value $<0.05$. Of the 446 genes, 200 genes were up-regulated, and the remaining 246 genes were down-regulated. We performed enrichment analyses of GO terms and KEGG pathways to determine physiological differences between variant 4 and [?]hfq E .coli . We used DAVID bioinformatics tool (Huang da et al., 2009) to identify the functions enriched within DEGs. The enriched terms are listed in Table 2.

Up-regulated DEGs were significantly enriched within cellular processes that are attributed to the ability of the cell to respond to stimulus, specifically acid stress. The GO enrichment results show that the genes involved in response to $\mathrm{pH}$ condition were up-regulated [intracellular $p H$ elevation (GO:0051454, $p$-value $=0.021)$ and response to $p H$ (GO:0009268, $p$-value $=0.031]$. In addition, other biological processes were also enriched. The tRNA methylation pathway (GO: 0030488, $p$-value $=0.018$ ) was up-regulated when Hfq was expressed. tRNA methylation protects tRNAs from degradation by $\mathrm{RNaseT}_{1}$ and RNaseA (Yokoyama et al., 1987). The putrescine catabolic process is one of the pathways that was significantly enriched (GO:0009447, $p$-value $=0.010$ ) within up-regulated DEGs. Putrescine is a polyamine and an essential biological molecule. Putrescine accounts for the majority of polyamines in $E$. coli and is associated with bacterial growth (Schneider et al., 2013; Takahashi \& Kakehi, 2009; Yoshida et al., 2004) by protecting $E$. coli against oxidative stress (A. Tkachenko et al., 2001). Specifically, putrescine was shown to be involved in the regulation of RpoS protein stability and at its translational level (A. G. Tkachenko \& Shumkov, 2004). RpoS is a general stress sigma factor $\sigma^{\mathrm{S}}$ (Battesti et al., 2011; Loewen et al., 1998), and the 5' UTR of rpoS mRNA interacts with the Hfq protein for efficient translation by opening a stem-loop structure that represses its translation initiation (Muffler et al., 1997). These enriched biological processes suggest that the optimal expression of Hfq protein enhances cell tolerance to cellular stresses.

The enrichment analysis of KEGG pathways identified 18 pathways (Table 2). Up-regulated DEGs were primarily involved in carbohydrate and energy metabolism pathways, particularly the "Glycolysis/Gluconeogenesis" and "Starch and sucrose metabolism." Alternatively, down-regulated DEGs were found to be significantly enriched in the "Citrate cycle (TCA cycle),$"(p$-value $=5.45 \mathrm{E}-9)$ which were consistent with the result of GO analysis (Table 2). In both GO and KEGG analyses, pathways related to energy metabolism were significantly enriched in down-regulated DEGs. As cells were sampled in the stationary phase, the main energy metabolism was repressed while secondary metabolite production was promoted, such as "Biosynthesis of antibiotics," owing to depletion of carbon sources and accumulation of toxic materials.

In conclusion, GO and KEGG analyses indicated that variant 4 increased the growth rate of $E$. coli by enhancing stress responses to mitigate harsh environments at high cell density.

Protein-protein interaction analysis

To identify the core functional modules in DEGs, we mapped the DEGs onto the PPI network obtained from the STRING database (Szklarczyk et al., 2015). Four highly interconnected sub-networks were identified using Cytoscape (Shannon et al., 2003) and MCODE (Bader \& Hogue, 2003). Three of the modules were composed of down-regulated genes, and one module was mostly composed of up-regulated ones (Fig. 2).

The up-regulated sub-network included proteins mostly involved in the acid resistance system of $E$. coli (Masuda \& Church, 2003): dctR, gadA, gadB, gadC, gadE,gadW, gadX, hdeA, hdeB, hdeD ,slp , and $y h i D$. In RNA-seq analysis comparing thehfq variant 4 with [?]hfq $E$. coli DH5 $\alpha$, up-regulated genes were in the sub-network, $h d e A, h d e B$, and gadEdemonstrated the highest fold-change. HdeA, HdeB, and HdeD are known as acid-resistance-related proteins (Table 3). Furthermore, the sub-network included the 
glutamate decarboxylase system (gad regulon) (M.-P. Castanie-Cornet et al., 1999; Lin et al., 1996). GadA and GadB encode for isozymes of glutamate decarboxylases catalyzing the conversion of glutamate to $\gamma$ aminobutyrate. GadC encodes a putative glutamate: $\gamma$-aminobutyrate antiporter (Hersh et al., 1996). GadE, GadX, and GadW were identified as a transcriptional activator of glutamate decarboxylase genes (M. P. Castanie-Cornet et al., 2010; Hommais et al., 2004; Tramonti et al., 2006). A recent study reported that the glutamate decarboxylase system is required for the protection of $E$.coli against metabolite stress in high-density cells (Mates et al., 2007).

Highly inter-connected down-regulated sub-networks were associated with succinate dehydrogenase ( $s d h A B D$ ), TCA cycle enzymes ( $s u c A B C D$ ), maltose transport activity, and glutamate synthase-related activity (Table 3). The $s d h$ and suc genes belong to a single operon (sdhABD-sucABCD) transcribed primarily from the sdh promoter (Cunningham \& Guest, 1998). SdhA, SdhB, and SdhD complex is a succinate dehydrogenase used in oxidative phosphorylation of the TCA cycle. The sucAB and sucCDencode for $\alpha$ ketoglutarate dehydrogenase and succinyl coenzyme A synthetase, respectively (Cronan \& Laporte, 2005). Both enzymes are involved in the cyclic flow of carbon from acetyl-CoA to carbon dioxide during aerobic growth. Thus, down-regulation of succinate dehydrogenase (sdhABD) and TCA cycle enzymes (sucABCD ) indicates that energy metabolism was repressed in the stationary phase (Szenk et al., 2017).

Only five genes were inter-connected in the last sub-network, including $\operatorname{car} A / B, g \ln A$, and $g l t B / D$. The $\operatorname{car} A$ and $\operatorname{car} B$ are in the $\operatorname{car}$ region and encode for two subunits of carbamoyl-phosphate synthetase (Mergeay et al., 1974), which catalyze the hydrolysis of glutamine to glutamate and ammonia (Thoden et al., 1998). The $g \ln A$ and $g l t B / D$ encode for a glutamine synthase that catalyzes the reaction of glutamate synthesis. Glutamate in $E$. coli is synthesized from $\alpha$-ketoglutarate, an intermediate in the TCA cycle. The TCA cycle and other related processes were down-regulated, and it is understandable that glutamate synthesis enzymes were consequently under expressed.

Optimized expression of GadE, a regulator of acid resistance

RNA-seq and network analyses identified an up-regulated subnetwork. Notably, node genes are mostly under the control of the GadE transcription factor, which is related to acid resistance. With the same logic, we additionally attempted to optimize the expression level of GadE. The RBS nucleotides of GadE were designed using RBSDesigner (Fig. 3A) to generate six variants (Table S3).

To investigate the effect of gadE on cell growth, plasmids harboring designed gadE variants were introduced into the $\mathrm{DH} 5 \alpha$ cell, and their cell growth was measured at $\mathrm{OD}_{600}$. As expected, expression of wild-type gadE and all gadEvariants resulted in an increase in their cell densities, indicating that additional expression of gadE helps cells grow better. As shown in Fig. 3B, additional expression of $h f q$ variant 4 in wild-type DH5 $\alpha$ resulted in higher growth $\left(\mathrm{OD}_{600}=4.22 \pm 0.14\right)$ than that of wild-type $\mathrm{DH} 5 \alpha\left(\mathrm{OD}_{600}=3.60 \pm 0.075\right)$. Similarly, additional expression of wild-type gadE in DH5 $\alpha$ increased cell growth $\left(\mathrm{OD}_{600}=4.30 \pm 0.14\right)$. Among the gadE variants, gadE variant 4 resulted in the maximum cell growth, by approximately $22.8 \%$ and $4.8 \%$ relative to that by wild-type DH5 $\alpha$ and $h f q$ variant 4 expressed in wild-type DH5 $\alpha$, respectively. The gadE variant 4 was designed to have a translational level of 0.1 , while that of wild-type gadE was 0.012 . Seemingly, additional expression of gadE (aside from genomicgadE ) with optimized translation efficiency increases cell growth (Fig. 3B).

Co-expression of gadE variants with $h f q$ variant 4 also demonstrated higher OD than wild-type DH5 $\alpha$ (Fig. $3 \mathrm{C})$. Of the sixgadE variants, gadE variants 4 and 6 co-expressed with $h f q$ variant 4 increased cell density by $27.5 \%$ and $29.7 \%$, respectively, when compared with that by wild-type DH5 $\alpha$. Thus, co-expression of both gadE and $h f q$ variants provided a better result. This could be because of the effect of hfq on gadEand its function as an acid resistant regulator, which helps ease cellular stress allowing the cells to grow better. However, none of the variants had higher OD than $h f q$ variant 4 expressed in[?]hfq DH5 $\alpha$. These results suggest that optimizing the expression of GadE also confers $E$. coli with the ability to grow faster and achieve greater cell density. This is consistent with the results of RNA-seq analysis: when $h f q$ expression is fine-regulated, cells grow faster by expressing more GadE proteins. 
Overall, the result confirmed our hypothesis that optimized Hfq expression promotes cell growth by enhancing acid resistance to overcome unflavored $\mathrm{pH}$ condition. We obtained higher increase in OD than previous strategies carried out at the same scale (Table 1) such as focusing on carbon flux redirection (Farmer \& Liao, 1997) and down-regulation of PTA and ACK using antisense RNA (Kim \& Cha, 2003).

\section{Conclusion}

This study proves the strong correlation between Hfq expression and $E$. coli growth and that the optimization of Hfq expression improves $E$. coli growth and regulates several pathways that participate in cellular stress tolerance at the highest cell density. However, one of our limitation in this study was the scale of experiments, which was performed in shaking flask, and flask culture provides limited environments and controls over cell growth. Thus, for further industrial application, it is feasible to scale-up from flask to bioreactor or fermentor in which we can regulate culture conditions. In addition, our approach to increase cell growth would be beneficial for constructing microbial cell factories with slow growing bacteria.

\section{Acknowledgments}

This work was supported by the National Research Foundation of Korea (NRF) grant, funded by the Korean government (MSIT) (No. NRF-2018R1A5A1025077). This research was also supported by the C1 Gas Refinery Program through the National Research Foundation of Korea (NRF), funded by the Ministry of Science, ICT and Future Planning (NRF-2016M3D3A1A01913244).

\section{Conflict of Interest Statement}

The authors declare that there are no conflicts of interests.

\section{References}

Ali Azam, T., Iwata, A., Nishimura, A., Ueda, S., \& Ishihama, A. (1999). Growth phase-dependent variation in protein composition of theEscherichia coli nucleoid. J Bacteriol, 181 (20), 6361-6370.

Anders, S., Pyl, P. T., \& Huber, W. (2015). HTSeq-a Python framework to work with high-throughput sequencing data. Bioinformatics, 31 (2), 166-169. doi:10.1093/bioinformatics/btu638

Bader, G. D., \& Hogue, C. W. (2003). An automated method for finding molecular complexes in large protein interaction networks. BMC Bioinformatics, 4, 2.

Baeshen, N. A., Baeshen, M. N., Sheikh, A., Bora, R. S., Ahmed, M. M., Ramadan, H. A., et al. (2014). Cell factories for insulin production.Microb Cell Fact, 13 , 141. doi:10.1186/s12934-014-0141-0

Battesti, A., Majdalani, N., \& Gottesman, S. (2011). The RpoS-mediated general stress response in Escherichia coli . Annu Rev Microbiol, 65 , 189-213. doi:10.1146/annurev-micro-090110-102946

Bauer, K. A., Ben-Bassat, A., Dawson, M., de la Puente, V. T., \& Neway, J. O. (1990). Improved expression of human interleukin-2 in high-cell-density fermentor cultures of Escherichia coli K-12 by a phosphotransacetylase mutant. Appl Environ Microbiol, 56 (5), 1296-1302.

Bentley, W. E., Mirjalili, N., Andersen, D. C., Davis, R. H., \& Kompala, D. S. (1990). Plasmid-encoded protein: the principal factor in the "metabolic burden" associated with recombinant bacteria.Biotechnology and bioengineering, 35 (7), 668-681.

Birnbaum, S., \& Bailey, J. E. (1991). Plasmid presence changes the relative levels of many host cell proteins and ribosome components in recombinant Escherichia coli . Biotechnol Bioeng, 37 (8), 736-745. doi:10.1002/bit.260370808

Briand, L., Marcion, G., Kriznik, A., Heydel, J. M., Artur, Y., Garrido, C., et al. (2016). A self-inducible heterologous protein expression system in Escherichia coli . Sci Rep, 6 , 33037. doi:10.1038/srep33037

Caron, M. P., Lafontaine, D. A., \& Masse, E. (2010). Small RNA-mediated regulation at the level of transcript stability. Rna Biology, 7 (2), 140-144. doi:DOI 10.4161/rna.7.2.11056 
Castanie-Cornet, M.-P., Penfound, T. A., Smith, D., Elliott, J. F., \& Foster, J. W. (1999). Control of acid resistance in Escherichia coli . Journal of bacteriology, 181 (11), 3525-3535.

Castanie-Cornet, M. P., Cam, K., Bastiat, B., Cros, A., Bordes, P., \& Gutierrez, C. (2010). Acid stress response in Escherichia coli : mechanism of regulation of gadA transcription by RcsB and GadE.Nucleic Acids Res, 38 (11), 3546-3554. doi:10.1093/nar/gkq097

Chao, Y., \& Vogel, J. (2010). The role of Hfq in bacterial pathogens. Curr Opin Microbiol, 13 (1), 24-33. doi:10.1016/j.mib.2010.01.001

Cronan, J. E., Jr., \& Laporte, D. (2005). Tricarboxylic Acid Cycle and Glyoxylate Bypass. EcoSal Plus, 1 (2). doi:10.1128/ecosalplus.3.5.2

Cunningham, L., \& Guest, J. R. (1998). Transcription and transcript processing in the sdh CDAB-sucABCD operon of Escherichia coli .Microbiology, 144 (8), 2113-2123.

Dambach, M., Irnov, I., \& Winkler, W. C. (2013). Association of RNAs with Bacillus subtilis Hfq. PLoS One, 8 (2), e55156. doi:10.1371/journal.pone.0055156

Farmer, W. R., \& Liao, J. C. (1997). Reduction of aerobic acetate production by Escherichia coli . Appl Environ Microbiol, 63 (8), 3205-3210.

Ferrer-Miralles, N., Domingo-Espín, J., Corchero, J. L., Vázquez, E., \& Villaverde, A. (2009). Microbial factories for recombinant pharmaceuticals. Microbial Cell Factories, 8 , 17. doi:10.1186/1475-2859-8-17. (Accession No. 19317892)

Folichon, M., Arluison, V., Pellegrini, O., Huntzinger, E., Regnier, P., \& Hajnsdorf, E. (2003). The poly(A) binding protein Hfq protects RNA from RNase E and exoribonucleolytic degradation. Nucleic Acids Res, 31 (24), 7302-7310. doi:10.1093/nar/gkg915

Glick, B. R. (1995). Metabolic load and heterologous gene expression.Biotechnol Adv, 13 (2), 247-261. doi:doi:10.1016/0734-9750(95)00004-A

Gottesman, S., McCullen, C., Guillier, M., Vanderpool, C., Majdalani, N., Benhammou, J., et al. (2006). Small RNA regulators and the bacterial response to stress. Paper presented at the Cold Spring Harbor symposia on quantitative biology.

Gupta, P., Aggarwal, N., Batra, P., Mishra, S., \& Chaudhuri, T. K. (2006). Co-expression of chaperonin GroEL/GroES enhances in vivo folding of yeast mitochondrial aconitase and alters the growth characteristics of Escherichia coli . Int J Biochem Cell Biol, 38 (11), 1975-1985. doi:10.1016/j.biocel.2006.05.013

Hernandez-Arranz, S., Sanchez-Hevia, D., Rojo, F., \& Moreno, R. (2016). Effect of Crc and Hfq proteins on the transcription, processing, and stability of the Pseudomonas putida CrcZ sRNA. RNA, 22 (12), 1902-1917. doi:10.1261/rna.058313.116

Hersh, B. M., Farooq, F. T., Barstad, D. N., Blankenhorn, D. L., \& Slonczewski, J. L. (1996). A glutamate-dependent acid resistance gene inEscherichia coli . J Bacteriol, 178 (13), 3978-3981. doi:10.1128/jb.178.13.3978-3981.1996

Hommais, F., Krin, E., Coppee, J. Y., Lacroix, C., Yeramian, E., Danchin, A., et al. (2004). GadE (YhiE): a novel activator involved in the response to acid environment in Escherichia coli .Microbiology, 150 (Pt 1), 61-72. doi:10.1099/mic.0.26659-0

Huang da, W., Sherman, B. T., \& Lempicki, R. A. (2009). Systematic and integrative analysis of large gene lists using DAVID bioinformatics resources. Nat Protoc, 4 (1), 44-57. doi:10.1038/nprot.2008.211

Jain, C., Deana, A., \& Belasco, J. G. (2002). Consequences of RNase E scarcity in Escherichia coli . Mol Microbiol, 43 (4), 1053-1064. doi:10.1046/j.1365-2958.2002.02808.x 
Jozala, A. F., Geraldes, D. C., Tundisi, L. L., Feitosa, V. A., Breyer, C. A., Cardoso, S. L., et al. (2016). Biopharmaceuticals from microorganisms: from production to purification. Braz J Microbiol, 47 Suppl 1 (Suppl 1), 51-63. doi:10.1016/j.bjm.2016.10.007

Kajitani, M., \& Ishihama, A. (1991). Identification and sequence determination of the host factor gene for bacteriophage Q beta.Nucleic Acids Res, 19 (5), 1063-1066. doi:10.1093/nar/19.5.1063

Kajitani, M., Kato, A., Wada, A., Inokuchi, Y., \& Ishihama, A. (1994). Regulation of the Escherichia coli $h f q$ gene encoding the host factor for phage Q beta. J Bacteriol, 176 (2), 531-534. doi:10.1128/jb.176.2.531534.1994

Kalscheuer, R., Stolting, T., \& Steinbuchel, A. (2006). Microdiesel:Escherichia coli engineered for fuel production.Microbiology, 152 (Pt 9), 2529-2536. doi:10.1099/mic.0.29028-0

Kim, J. Y., \& Cha, H. J. (2003). Down-regulation of acetate pathway through antisense strategy in Escherichia coli : Improved foreign protein production. Biotechnology and bioengineering, 83 (7), 841-853.

Korz, D. J., Rinas, U., Hellmuth, K., Sanders, E. A., \& Deckwer, W. D. (1995). Simple fed-batch technique for high cell density cultivation ofEscherichia coli . J Biotechnol, 39 (1), 59-65. doi:10.1016/01681656(94)00143-z

Lee, J. H., Heo, M. A., Seo, J. H., Kim, J. H., Kim, B. G., \& Lee, S. G. (2008). Improving the growth rate of Escherichia coli DH5 $\alpha$ at low temperature through engineering of GroEL/S chaperone system.Biotechnol Bioeng, 99 (3), 515-520. doi:10.1002/bit.21616

Lee, S. K., Chou, H., Ham, T. S., Lee, T. S., \& Keasling, J. D. (2008). Metabolic engineering of microorganisms for biofuels production: from bugs to synthetic biology to fuels. Curr Opin Biotechnol, 19 (6), 556-563. doi:10.1016/j.copbio.2008.10.014

Li, Z., \& Deutscher, M. P. (2002). RNase E plays an essential role in the maturation of Escherichia coli tRNA precursors. RNA, 8 (1), 97-109. doi:10.1017/s1355838202014929

Lin, J., Smith, M. P., Chapin, K. C., Baik, H. S., Bennett, G. N., \& Foster, J. W. (1996). Mechanisms of acid resistance in enterohemorrhagicEscherichia coli . Appl Environ Microbiol, 62 (9), 3094-3100.

Loewen, P. C., Hu, B., Strutinsky, J., \& Sparling, R. (1998). Regulation in the rpoS regulon of Escherichia coli .Canadian journal of microbiology, 44 (8), 707-717. doi:10.1139/cjm-44-8-707

Markl, H., Zenneck, C., Dubach, A. C., \& Ogbonna, J. C. (1993). Cultivation of Escherichia-Coli to High Cell Densities in a Dialysis Reactor. Applied microbiology and biotechnology, 39 (1), 48-52.

Masuda, N., \& Church, G. M. (2003). Regulatory network of acid resistance genes in Escherichia coli . Mol Microbiol, 48 (3), 699-712. doi:10.1046/j.1365-2958.2003.03477.x

Mates, A. K., Sayed, A. K., \& Foster, J. W. (2007). Products of theEscherichia coli acid fitness island attenuate metabolite stress at extremely low $\mathrm{pH}$ and mediate a cell density-dependent acid resistance. $J$ Bacteriol, 189 (7), 2759-2768. doi:10.1128/JB.01490-06

Matsui, T., Yokota, H., Sato, S., Mukataka, S., \& Takahashi, J. (1989). Pressurized Culture of Escherichia-Coli for a High-Concentration.Agricultural and biological chemistry, 53 (8), 2115-2120. doi:Doi 10.1080/00021369.1989.10869644

Mergeay, M., Gigot, D., Beckmann, J., Glansdorff, N., \& Pierard, A. (1974). Physiology and genetics of carbamoylphosphate synthesis inEscherichia coli K12. Mol Gen Genet, 133 (4), 299-316. doi:10.1007/bf00332706

Mortazavi, A., Williams, B. A., McCue, K., Schaeffer, L., \& Wold, B. (2008). Mapping and quantifying mammalian transcriptomes by RNA-Seq.Nat Methods, 5 (7), 621-628. doi:10.1038/nmeth.1226 
Muffler, A., Traulsen, D. D., Fischer, D., Lange, R., \& Hengge-Aronis, R. (1997). The RNA-binding protein HF-I plays a global regulatory role which is largely, but not exclusively, due to its role in expression of the sigmaS subunit of RNA polymerase in Escherichia coli .Journal of bacteriology, 179 (1), 297-300.

Na, D., \& Lee, D. (2010). RBSDesigner: software for designing synthetic ribosome binding sites that yields a desired level of protein expression. Bioinformatics, 26 (20), 2633-2634. doi:10.1093/bioinformatics/btq458

Nakamura, T., Tanaka, M., Maruyama, A., Higashi, Y., \& Kurusu, Y. (2004). A nonconserved carboxyterminal segment of GroEL contributes to reaction temperature. Biosci Biotechnol Biochem, 68 (12), 24982504. doi:10.1271/bbb.68.2498

Nakano, K., Rischke, M., Sato, S., \& Markl, H. (1997). Influence of acetic acid on the growth of Escherichia coli K12 during high-cell-density cultivation in a dialysis reactor. Appl Microbiol Biotechnol, 48 (5), 597-601. doi:10.1007/s002530051101

Ow, M. C., \& Kushner, S. R. (2002). Initiation of tRNA maturation by RNase E is essential for cell viability in E. coli . Genes Dev, 16 (9), 1102-1115. doi:10.1101/gad.983502

Quianzon, C. C., \& Cheikh, I. (2012). History of insulin. J Community Hosp Intern Med Perspect, 2 (2). doi:10.3402/jchimp.v2i2.18701

Ramos, C. R., Abreu, P. A., Nascimento, A. L., \& Ho, P. L. (2004). A high-copy T7 Escherichia coli expression vector for the production of recombinant proteins with a minimal N-terminal His-tagged fusion peptide. Braz J Med Biol Res, 37 (8), 1103-1109. doi:10.1590/s0100-879x2004000800001

Rezaei, M., \& Zarkesh-Esfahani, S. H. (2012). Optimization of production of recombinant human growth hormone in Escherichia coli . Journal of research in medical sciences : the official journal of Isfahan University of Medical Sciences, 17 (7), 681-685.

Riesenberg, D. (1991). High-cell-density cultivation of Escherichia coli . Current Opinion in Biotechnology, 2 (3), 380-384. doi:10.1016/s0958-1669(05)80142-9

Sanchez-Garcia, L., Martin, L., Mangues, R., Ferrer-Miralles, N., Vazquez, E., \& Villaverde, A. (2016). Recombinant pharmaceuticals from microbial cells: a 2015 update. Microb Cell Fact, 15 , 33. doi:10.1186/s12934-016-0437-3

Schein, C. H. (1989). Production of Soluble Recombinant Proteins in Bacteria. Nat Biotechnol, 7 (11), 1141-1147.

Schneider, B. L., Hernandez, V. J., \& Reitzer, L. (2013). Putrescine catabolism is a metabolic response to several stresses inEscherichia coli . Mol Microbiol, 88 (3), 537-550.

Sezonov, G., Joseleau-Petit, D., \& D'Ari, R. (2007). Escherichia coli physiology in Luria-Bertani broth. J Bacteriol, 189 (23), 8746-8749. doi:10.1128/JB.01368-07

Shannon, P., Markiel, A., Ozier, O., Baliga, N. S., Wang, J. T., Ramage, D., et al. (2003). Cytoscape: a software environment for integrated models of biomolecular interaction networks. Genome Res, 13 (11), 2498-2504. doi:10.1101/gr.1239303

Shiloach, J., \& Fass, R. (2005). Growing E. coli to high cell density-a historical perspective on method development.Biotechnol Adv, 23 (5), 345-357. doi:10.1016/j.biotechadv.2005.04.004

Sittka, A., Pfeiffer, V., Tedin, K., \& Vogel, J. (2007). The RNA chaperone Hfq is essential for the virulence of Salmonella typhimurium . Mol Microbiol, 63 (1), 193-217. doi:10.1111/j.1365-2958.2006.05489.x

Son, Y. J., Ryu, A. J., Li, L., Han, N. S., \& Jeong, K. J. (2016). Development of a high-copy plasmid for enhanced production of recombinant proteins in Leuconostoc citreum . Microb Cell Fact, 15 (1), 12. doi:10.1186/s12934-015-0400-8 
Studier, F. W., \& Moffatt, B. A. (1986). Use of bacteriophage T7 RNA polymerase to direct selective high-level expression of cloned genes.J Mol Biol, 189 (1), 113-130. doi:10.1016/0022-2836(86)90385-2

Szenk, M., Dill, K. A., \& de Graff, A. M. R. (2017). Why Do Fast-Growing Bacteria Enter Overflow Metabolism? Testing the Membrane Real Estate Hypothesis. Cell Syst, 5 (2), 95-104. doi:10.1016/j.cels.2017.06.005

Szklarczyk, D., Franceschini, A., Wyder, S., Forslund, K., Heller, D., Huerta-Cepas, J., et al. (2015). STRING v10: protein-protein interaction networks, integrated over the tree of life. Nucleic Acids Res, 43 (Database issue), D447-452. doi:10.1093/nar/gku1003

Szklarczyk, D., Morris, J. H., Cook, H., Kuhn, M., Wyder, S., Simonovic, M., et al. (2017). The STRING database in 2017: quality-controlled protein-protein association networks, made broadly accessible.Nucleic Acids Res, 45 (D1), D362-D368. doi:10.1093/nar/gkw937

Takahashi, T., \& Kakehi, J.-I. (2009). Polyamines: ubiquitous polycations with unique roles in growth and stress responses. Annals of Botany, 105 (1), 1-6.

Tegel, H., Ottosson, J., \& Hober, S. (2011). Enhancing the protein production levels in Escherichia coli with a strong promoter.FEBS J, 278 (5), 729-739. doi:10.1111/j.1742-4658.2010.07991.x

Thoden, J. B., Miran, S. G., Phillips, J. C., Howard, A. J., Raushel, F. M., \& Holden, H. M. (1998). Carbamoyl phosphate synthetase: caught in the act of glutamine hydrolysis. Biochemistry, 37 (25), 88258831. doi:10.1021/bi9807761

Tkachenko, A., Nesterova, L., \& Pshenichnov, M. (2001). The role of the natural polyamine putrescine in defense against oxidative stress inEscherichia coli . Arch Microbiol, 176 (1-2), 155-157.

Tkachenko, A. G., \& Shumkov, M. S. (2004). Role of putrescine in regulation of the sigmaS subunit of RNA polymerase in Escherichia coli cells on transition to stationary phase. Biochemistry (Mosc), 69 (8), 876-882.

Tolentino, G. J., Meng, S.-Y., Bennett, G. N., \& San, K.-Y. (1992). A pH-regulated promoter for the expression of recombinant proteins inEscherichia coli . Biotechnology Letters, 14 (3), 157-162. doi:10.1007/bf01023351

Tramonti, A., De Canio, M., Delany, I., Scarlato, V., \& De Biase, D. (2006). Mechanisms of transcription activation exerted by GadX and GadW at the gadA and gadBC gene promoters of the glutamate-based acid resistance system in Escherichia coli . J Bacteriol, 188 (23), 8118-8127. doi:10.1128/JB.01044-06

Vytvytska, O., Jakobsen, J. S., Balcunaite, G., Andersen, J. S., Baccarini, M., \& von Gabain, A. (1998). Host factor I, Hfq, binds toEscherichia coli ompA mRNA in a growth rate-dependent fashion and regulates its stability. Proc Natl Acad Sci U S A, 95 (24), 14118-14123. doi:10.1073/pnas.95.24.14118

Wong, M., Wright, M., Woodley, J. M., \& Lye, G. J. (2009). Enhanced recombinant protein synthesis in batch and fed-batch Escherichia coli fermentation based on removal of inhibitory acetate by electrodialysis. Journal of Chemical Technology \&3 Biotechnology, 84 (9), 1284-1291.

Yokoyama, S., Watanabe, K., \& Miyazawa, T. (1987). Dynamic structures and functions of transfer ribonucleic acids from extreme thermophiles.Adv Biophys, 23, 115-147.

Yoshida, M., Kashiwagi, K., Shigemasa, A., Taniguchi, S., Yamamoto, K., Makinoshima, H., et al. (2004). A unifying model for the role of polyamines in bacterial cell growth, the polyamine modulon. $J$ Biol Chem, 279 (44), 46008-46013. doi:10.1074/jbc.M404393200

Yoshimoto, H., Fukushige, T., Yonezawa, T., \& Sone, H. (2002). Genetic and physiological analysis of branched-chain alcohols and isoamyl acetate production in Saccharomyces cerevisiae. Appl Microbiol Biotechnol, 59 (4-5), 501-508. doi:10.1007/s00253-002-1041-5 
Zawada, J., \& Swartz, J. (2005). Maintaining rapid growth in moderate-density Escherichia coli fermentations. Biotechnol Bioeng, 89 (4), 407-415. doi:10.1002/bit.20369

\section{Figure Legends}

Figure 1. Constructed $h f q$ variants and their effect on cell growth

(A) Constructed $h f q$ gene structure and RBS variants. We designed nucleotides denoted as 'N': four nucleotides upstream of Shine Dalgarno (SD) and eight nucleotides downstream of SD. The designed translation efficiencies were $0.0001,0.001,0.01,0.1$, and 0.3 . To avoid prolonged transcription downstream of the $h f q$ gene, a transcription terminator was added to the gene construct. (B)Green fluorescent protein (GFP)tagged Hfq expression levels. The $f q$ variant 4 demonstrates higher Hfq expression ( $>4$-fold) levels than the wild-type strain and other variants, while $h f q$ variant 1 demonstrated the lowest GFP intensity. Although variant 5 was designed to have the highest translational efficiency, its expression was similar to that of $h f q$ variants 2 and 3. (C) Growth measurements of the[?]hfq Escherichia coli strain (control strain) with and without $h f q$ variants. The control strain and $h f q$ variant 1 demonstrate the lowest growth. The $h f q 2,3$, and 5 variants and wild-type $E$. coli $\mathrm{DH} 5 \alpha$ demonstrate similar growth rates. Alternatively, the $h f q$ variant 4 demonstrate higher growth and maximum $\mathrm{OD}_{600}$ than those of the control strain $(66.8 \%$ higher than the control strain). EV denotes an empty vector.

Figure 2 . Protein-protein interaction (PPI) network and four highly interconnected subnetworks.

Red and blue denote up-regulated and down-regulated genes, respectively.

Figure 3. Constructed gadE variants and their effect on cell growth

(A) Constructed gadE gene structure and its ribosome-binding site (RBS) variants. We designed the nucleotides denoted as 'N': four nucleotides upstream of Shine Dalgarno (SD) and eight nucleotides downstream SD. The designed translation efficiencies were $0.0001,0.001,0.01,0.1,0.2$, and 0.3 . To avoid prolonged transcription downstream of the gadE gene, a transcription terminator was added to the gene construct. (B) Maximum $\mathrm{OD}_{600}$ of DH5 $\alpha$ cells expressing the wild typegadE, gadE variants, and $h f q$ variant 4.(C) Maximum $\mathrm{OD}_{600}$ of [?] $f f q \mathrm{DH} 5 \alpha$ cells co-expressing the wild-type gadE or gadE variants $+h f q$ variant 4.

\section{Hosted file}

Table 1.docx available at https://authorea.com/users/338064/articles/464070-optimizedexpression-of-hfq-protein-increases-escherichia-coli-growth-by-enhancing-acid-resistance

Hosted file

Table 2.docx available at https://authorea.com/users/338064/articles/464070-optimizedexpression-of-hfq-protein-increases-escherichia-coli-growth-by-enhancing-acid-resistance

\section{Hosted file}

Table 3.docx available at https://authorea.com/users/338064/articles/464070-optimizedexpression-of-hfq-protein-increases-escherichia-coli-growth-by-enhancing-acid-resistance 
A

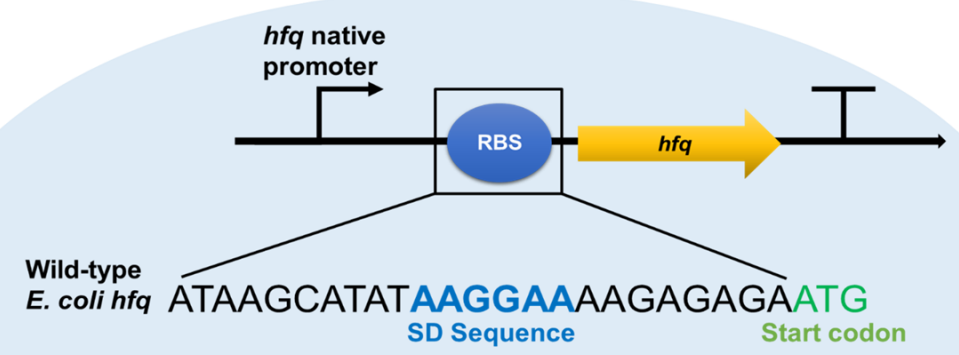

Variant ATAAGCNNNNAAGGAANNNNNNNNATG

Variant nucleotides Variant nucleotides

B

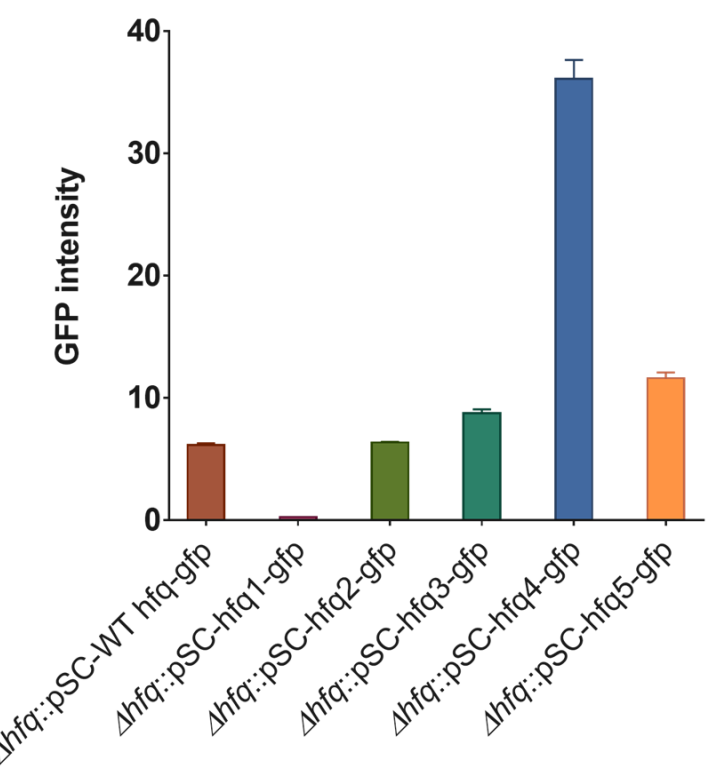

C

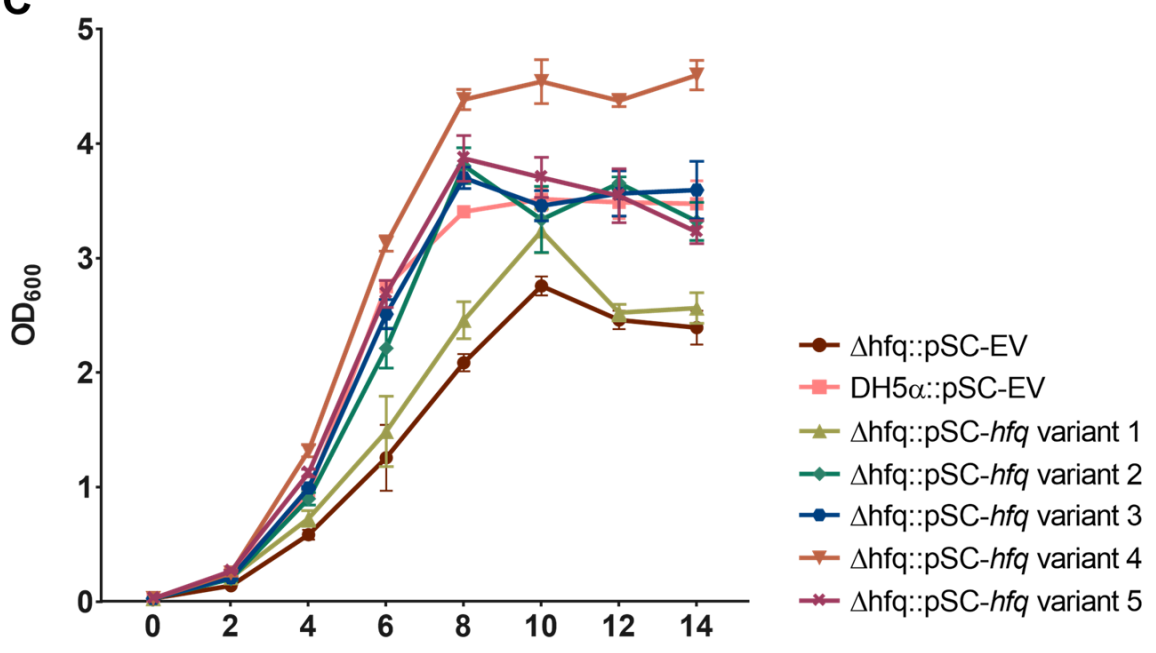

Time (h) 


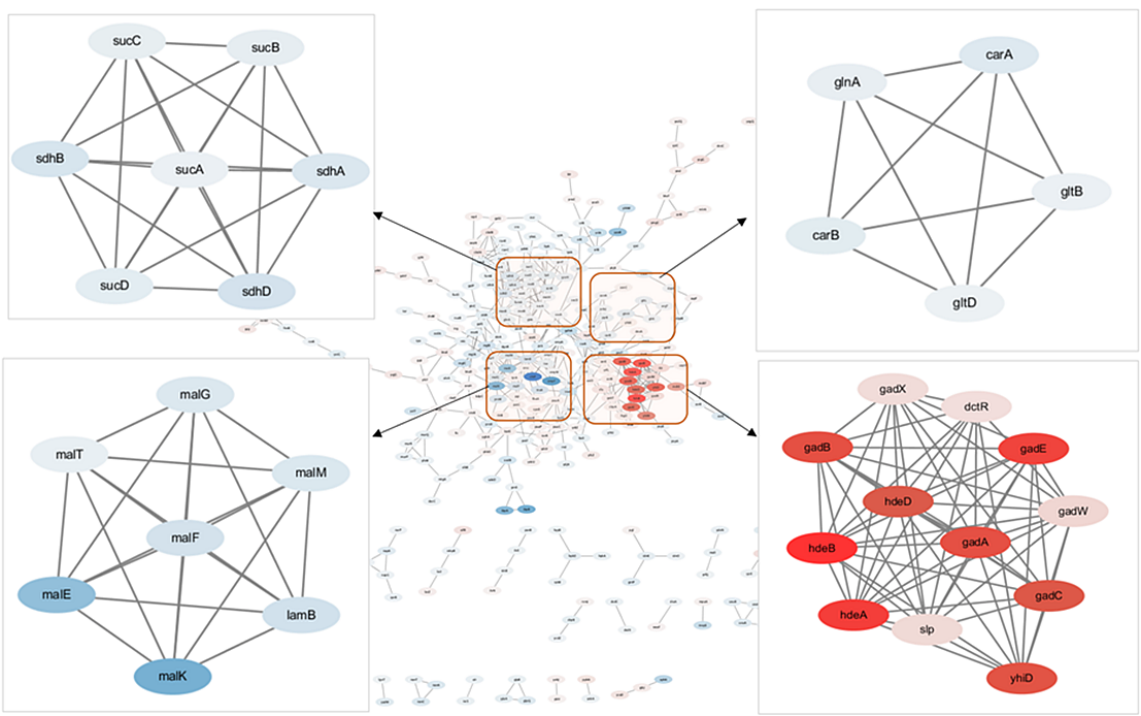




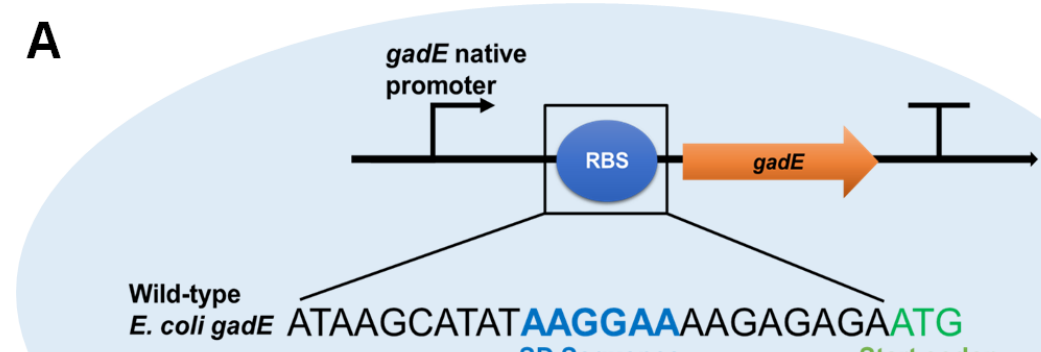

SD Sequence Start codon

Variant ATAAGCNNNNAAGGAANNNNNNNNATG

Variant nucleotides Variant nucleotides

B
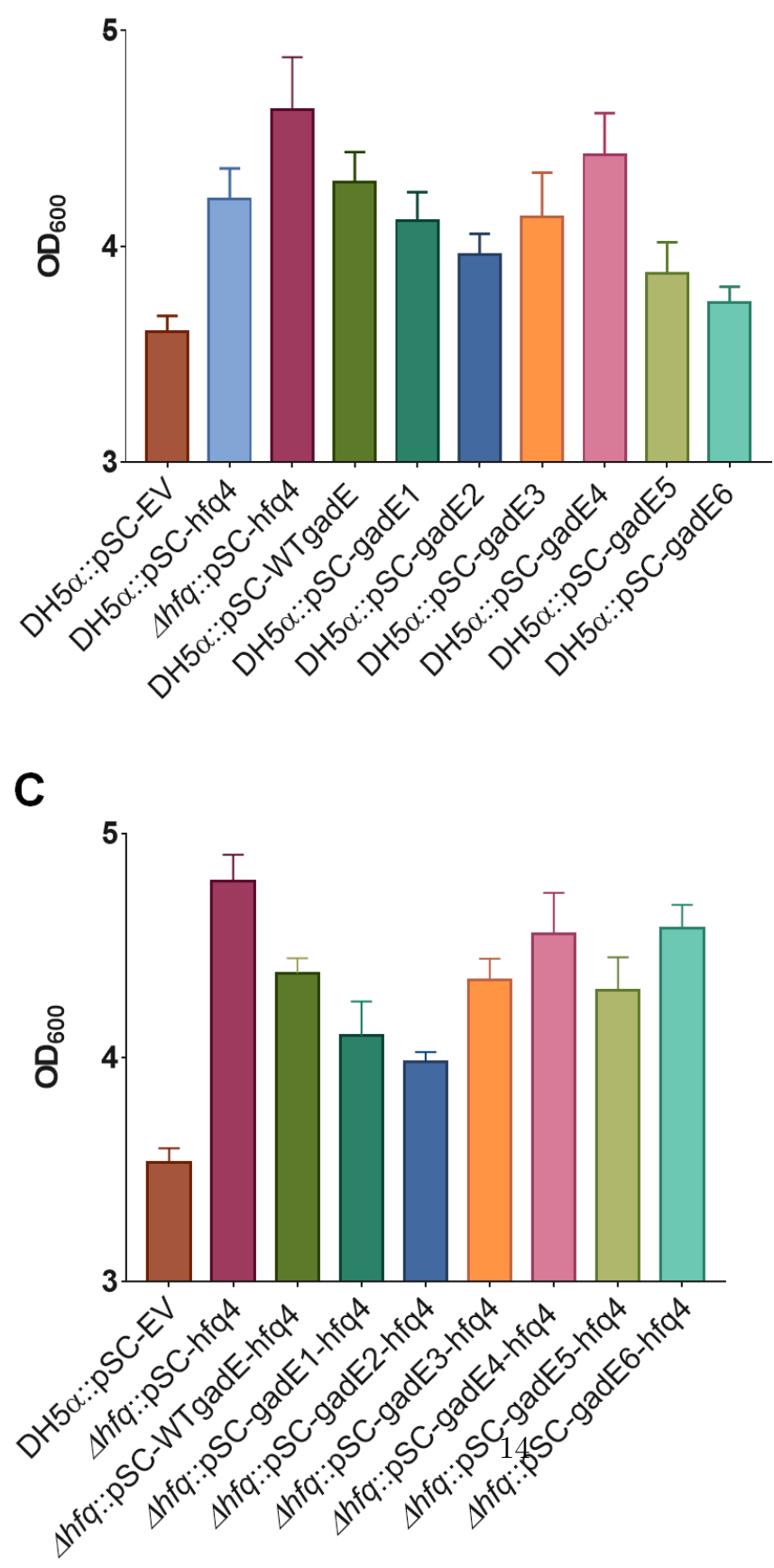